\title{
Celiac \& gluten intolerance: a wellness perspective
}

\begin{abstract}
The popularity of the gluten-free diet is driven by misconceptions concerning its efficacy for everything from weight control to sports performance. It is time to step back and review the current state of diagnostic methods, diet treatment, and the health-related outcomes of celiac and gluten-sensitive individuals. This review was undertaken to propose changes to wellness promotion and food industry practices for people who are in the gluten intolerant spectrum, and to identify opportunities for research in nutrition and wellness products and services.
\end{abstract}

Keywords: celiac disease, non-celiac gluten sensitivity, osteoporosis, coronary heart disease, wellness
Volume I Issue 5 - 2014

Patricia Grace-Farfaglia

Department of Nutritional Sciences, University of Connecticut, USA

Correspondence: Patricia Grace-Farfaglia, Department of Nutritional Sciences, University of Connecticut, 99 East Main Street, Waterbury, CT 06702, Provo, Utah, USA, Tel 2032700097, Email grace.farfaglia@gmail.com

Received: August 28, 2014 | Published: October 20, 2014

\begin{abstract}
Abbreviations: CD, celiac disease; AGA, american gastroenterological association; ESPGHAN, european society for pediatric gastroenterology, hepatology, and nutrition; NCGS, nonceliac gluten sensitivity; HLA, human leukocyte antigen; GFD, glutenfree diet; FODMAPS, fermentable monosaccharides and polyols; ELISA, enzyme-linked immunosorbent assay; SPT, skin prick test; IDL, intraepithelial duodenal lymphocytosis; IgE, immunoglobulin E; EIWA, exercise-induced anaphylaxis; IgA, immunoglobulin A; IgG, immunoglobulin G; IgG-EMA, IgG anti-endomysium antibodies; TGA, transglutaminase antibodies; tTG, tissue transglutaminase; DH, dermatitis herpetiformis; IF, immunofluorescence; GOS, galactooligosaccharides; CDAT, celiac dietary adherence test; NRCD, nonresponsive celiac disease; GCED, gluten contamination elimination diet; CSI, celiac symptom index; TTB, tobacco tax and trade bureau; ROS, reactive oxidative species; DHA, docosahexaenoic acid
\end{abstract}

\section{Introduction}

Celiac disease is a T cell-mediated autoimmune disease triggered by digestion-resistant immunotoxic peptides from ingestion of gluten. Gluten is a glycosylated storage protein found in wheat, rye, and barley, and used in the production of many processed foods. The disease has a wide array of manifestations, affecting the health of the gastrointestinal, integumentary, immune, and central nervous systems. The current ESPGHAN (European Society for Pediatric Gastroenterology, Hepatology, and Nutrition) American Gastroenterological Association (AGA) guidelines for the diagnosis of celiac disease were published to improve the accuracy of serologic testing and reduce the high variability in interpretation of duodenal biopsies. ${ }^{1-3}$ Experience with serologic testing has led to greater confidence in the method's ability to detect $\mathrm{CD}$, a disease that affects an estimated $1 \%$ of the population in the United States and Europe. 4,5 Estimates from recent serologic studies in India suggest that the prevalence of CD is between 0.056 and $1.14 \%$, an estimate that is larger than previously reported, but likely due the silent aspect of adult onset symptoms. ${ }^{6-8}$ The number of confirmed cases is also rising in China, where previously it was a rarity. ${ }^{9}$ The practice of active case-finding by screening high risk groups, such as first degree relatives, type 1 diabetes, or autoimmune thyroid disease, is becoming common practice in Europe and North America, but it remains a largely undiagnosed condition..$^{10,11}$ Individuals who are sensitive to gluten, but do not fit the full diagnostic criteria for $\mathrm{CD}$, have been assigned to categories known as "latent celiac" or non-celiac gluten sensitivity (NCGS). Italian researchers followed latent celiac patients who had positive serologic markers (TTG and/or anti-endomysial antibodies) and carried the human leukocyte antigen (HLA)-DQ2/DQ-8 haplotypes, but initial biopsies showed no small intestinal villous flattening. ${ }^{12}$ Within fouryears $30 \%$ participants $(n=127)$, were eventually diagnosed with $\mathrm{CD}$. Australian researchers have demonstrated in a double blind, randomly controlled study that some individuals become symptomatic when challenged with gluten, but otherwise do not meet the diagnostic criteria for CD. ${ }^{13,14}$ Proposed triggers of NCGS include gluten and other wheat proteins, food additives, and a diet rich in fermentable Monosaccharides and Polyols (FODMAPS). ${ }^{15,16}$ Some forms of neurologic dysfunction are also related to NCGS, such as gluten ataxia, encephalopathy, epilepsy, stiff-man syndrome, and myoclonic ataxia. ${ }^{17}$ Gluten-intolerant patients present with neurological manifestations, rather than the classic gastrointestinal symptoms, yet possess circulating antibodies to gliadin and to at least one type of transglutaminase. The best estimate for the incidence of gluten-sensitivity in the US population is derived from self-reported gluten-free diet (GFD) from the NHANES survey, and is approximately $.5 \%$, and some authors estimate that it is as high as $6 \%{ }^{15,18}$

Wheat allergy, an IgE mediated reaction to omega-5 gliadin fraction of gliadin protein, is found in only $1 \%$ of the general US population. This group includes "Baker's asthma," the leading cause of occupational disease in the baking industry that affects between one and 10 cases per 1000, and exercise-induced anaphylaxis (EIWA) or food-triggered-exercise induced-anaphylaxis with an unknown prevalence. ${ }^{19-22}$ Wheat allergy is diagnosed by serum titer for $\operatorname{IgE}$ $(>2 \mathrm{KU} / \mathrm{L})$, and an enzyme-linked immunosorbent assay (ELISA test) to determine the immunoreactivity to the fractions $\omega-5$ gliadin and $\omega-1.2$ gliadin, and by the skin prick test (SPT). ${ }^{23}$ Neither NCGS nor wheat allergy falls under the diagnosis of celiac disease, but are part of a spectrum of individuals who must avoid gluten containing foods for their health.

\section{The rising tide of gluten-free consumers}

Celiac is a disease with a highly variable clinical presentation. Prior to the publication of the 2012 ESPGHAN guidelines, the process 
of making the diagnosis relied heavily on the gold standard biopsy, but many clinicians have changed their clinical practice as they developed confidence in the accuracy of serologic testing. Primary providers are more willing to use serologic testing for case finding in high risk groups, such as chronic anemia, diabetes, and Grave's disease. ${ }^{24,25}$ Interpretation of the serologic tests is complicated by the high incidence of $\operatorname{IgA}$ deficiency in CD resulting in a reduction in IgA class antibodies against gliadin being. ${ }^{26} \mathrm{IgG}$ anti-endomysium antibodies (IgG-EMA) are accurate biomarkers for CD in patients with selective IgA deficiency. The "gold standard" for the diagnosis of CD is a histological examination of tissue samples in the duodenum with a finding of villous blunting and intraepithelial duodenal lymphocytosis (IDL) graded according to the Marsh-Oberhuber classification. ${ }^{27}$ Unfortunately, even the biopsy may provide false negative findings due problems with specimen processing, variability of the distribution of villous flattening along the duodenum, extent of IDL and intraepithelial lymphocyte variability between biopsy sites in the duodenum. ${ }^{28-30}$ But the lack of industry-wide assay standardization explains some of the hesitancy to forgo a biopsy for confirmation, except in the case where antibody test results are 10times greater than the upper limit of normal. ${ }^{31}$

In the past a typical patient presented with classical clinical signs that include digestive problems, malabsorption, and/or neurological manifestations, such as ataxia, depression, dementia, and/or peripheral neuropathy. The various tests for celiac disease and their published accuracies are displayed in Table 1. Celiac disease and gluten sensitivity have multi-factorial origins which are a combination of genetic, epigenetic, and environmental conditions leading to immune dysfunction associated with symptoms occurring after gluten ingestion, as seen in Table 2. Due to improved screening in the US more adult-onset cases fall into the asymptomatic (silent), potential, or latent categories. ${ }^{32}$ Regardless of symptoms, a patient testing positive for IgA tissue anti-transglutaminase antibodies (TGA) or endomysial antibodies (IgA-EMA), who has the DQ2 and DQ8 HLA heterodimers, but a "marginally positive" pathology (grade 1)is classified in the latent category. Using a simple " 4 out of 5 " rule the diagnosis of $\mathrm{CD}$ is made if four of these symptoms are found: classic gastrointestinal symptoms of weight loss and malnutrition; (HLA)DQ2 or DQ8 genotypes; seropositive values for TGA or EMA; villous flattening in the duodenum; and improvement of symptoms on a GFD.$^{33}$ Case finding strategies to improve the $\mathrm{CD}$ diagnosis rate have been proposed for the primary care setting. ${ }^{34}$ Researchers in Utah have developed a novel approach to facilitating $\mathrm{CD}$ screening by using the results of tissue transglutaminase (tTG) IgA and positive duodenal biopsies from a regional healthcare system database to build a predictive model for near-neighbor-derived probability estimates. ${ }^{35}$ Locally derived probabilities are likely more accurate than published estimates and are useful to screen potential CD cases and improve treatment outcomes in the community.

Like classic $\mathrm{CD}$, individuals with dermatitis herpetiformis (DH) also carry the $\mathrm{CD}$ genotype, but the symptoms are distinguished by a blistering rash initiated by granular IgA deposits in the skin, neutrophils, and inflammatory changes in the epidermis. ${ }^{36}$ Diagnosis is confirmed by a skin "punch" biopsy sampling tissue adjacent to active lesions by direct immunofluorescence (IF) of IgA endomysial antibodies (IgA-EMA) which characteristically form a granular pattern. ${ }^{37} \mathrm{DH}$ is distinguished by the presence of IgA-anti-TG3 or IgA-anti-TG6, rather than IgA-TG2 auto antibodies..$^{38}$ Anemia from the inflammatory changes in the mucosa may result from the malabsorption of iron, folate, and B12. ${ }^{37,39} \mathrm{DH}$ may disappear during spontaneous periods of remission lastingmonths toyears where the patient can resume eating a normal diet in the absence of skin and gastrointestinal symptoms. ${ }^{40,41}$ Because of the relapsing and remitting nature of $\mathrm{DH}$, and the recent findings of single-nucleotide variations associated with it, different environmental triggers have been proposed, including obesity. ${ }^{42} \mathrm{~A}$ large Danish birth cohort study reported that the risk of DH increases $14 \%$ ( $95 \% \mathrm{CI}, 1 \%$ to $30 \%)$ per unit of body mass index (BMI). ${ }^{43}$

Celiac disease is an adaptive immune response to gluten leading to a greater likelihood of developing other autoimmune disorders. The ability to screen, test and treat $\mathrm{CD}$ in each diagnostic category has long-term health effects. Symptomatic and latent forms have the same mortality risk, regardless of whether villus atrophy and crypt hyperplasia is present or not. ${ }^{44}$ It is likely that more genetic variants will be identified in the future, such as those associated with FRMD4B (3p14.1) and MYO9B. ${ }^{42,45}$

\section{Celiac or gluten sensitive?}

In a study screening high-risk groups, the frequency of celiac disease (CD)in the US primary care practice is estimated to be 11.6 per thousand visits, 95\% CI $[6.8,16.4] \mathrm{P}<0.001) .{ }^{34}$ From a nationally representative sample, the weighted prevalence rate was reported as $0.71,95 \% \mathrm{CI}[0.58-0.86]$, which is similar to the incidence in most European countries. ${ }^{46}$ Gluten-free diet adherence had a weighted rate of $0.63,95 \%$ CI [0.36-1.07]. NHANES data from 2009-2010 reported a weighted rate of $0.548 \%, 95 \%$ CI $[0.206,0.889]$ for those following a GF diet. ${ }^{18}$ The only population survey from the United Kingdom reported that $13 \%$ of the respondents were self-described "gluten sensitive," and only .8\% had a confirmed diagnosis of CD. ${ }^{47}$ In addition, the authors performed a case finding survey of primary care providers, and subsequently screened patients by symptoms and self-report of relief by a GFD. A subset of participants $(n=200)$ volunteered for a prospective study which included tTG/EMA assays, vitamin tests, and a "modified gluten challenge" consisting of 3 grams of gluten for twoweeks as suggested by Leffler et al. ${ }^{48}$ The authors reported that $7 \%$ of the subjects were confirmed cases of CD $(n=14)$, and $93 \%(\mathrm{n}=186)$ were classified as NCGS. A significant number of subjects in the NCGS group $(53 \%)$ were HLA-DQ2/8 positive, and this was greater than the $16.0 \%$ NCGS reported in American and Australian studies. ${ }^{49,50}$ A prospective multicenter study in Italy of over 12,000 consecutive patients identified $3.19 \%$ new CD cases and NCGS in $2.77 \%$, suggesting that a population estimate of NCGS may be equal or slightly higher than $1 \% .^{51}$ This is the best estimate to date for an emerging syndrome that is distinguished primarily to symptoms following gluten abstinence and challenge.

Compliance to a gluten-free diet presents a challenge to the sufferer because perceptible symptoms may be delayed or imperceptible after a period of gut rehabilitation. It has been observed that patient selfreports become less reliable over time compared to serologic testing. ${ }^{52}$ The Italian "CD-Watch" surveillance program used an annual t-TG antibody test to identify risky diet behaviors of its participants who were subsidized with gluten-free foods..$^{53}$ Over a 5-year period, subjects in the CD-Watch program achieved an overall compliance rate of $91 \%$. Those initially classified as persistently or fluctuating positive serology changed to persistently t-TG negative resulting in a shift from the initial annual compliance rate of $82 \%$ to $93 \%$ atyear 5 . "CD-Watch" illustrates the level of vigilance needed to coach patients into better adherence. 
Table I Accuracy of celiac tests

\begin{tabular}{|c|c|c|c|}
\hline $\begin{array}{l}\text { Celiac disease-specific } \\
\text { tests }\end{array}$ & Sensitivity(range) & Specificity(range) & Positive/negative predictive value \\
\hline IgA anti-tTG & $>95.0 \%(73.0-100)$ & $>95.0 \%(77.8-100)$ & $85.71 \% / 99.92 \%$ \\
\hline $\lg G$ anti-tTG & Variable (I2.6-99.3) & Variable $(86.3-100)$ & $86.42 \%$ / 99.95\% \\
\hline IgA EMA & $>90 \%(82.6-100)$ & $98.2 \%$ ( (94.7-100) & $77.73 \% / 99.8 \%$ \\
\hline $\operatorname{lgG}$ dGP & $>90 \%(80.1-98.6)$ & $>90.0 \%(80.1-98.6)$ & $98.9 \% / 95.2 \%$ \\
\hline $\begin{array}{l}\text { Rapid Point of Care Test } \\
\text { Kit }\end{array}$ & $94.35 \%(88.71-97.69)$ & $96.15 \%(90.44-98.92)$ & $94.5 \% / 96.2 \%$ \\
\hline HLA-DQ2 or HLA-DQ8 & $91.0(82.6-97.0)$ & $54.0(\mid 2.0-68.0)$ & $\begin{array}{l}100 \%(\mathrm{Cl}, 79-100) / \\
100 \%(\mathrm{Cl}, 98.6-100)\end{array}$ \\
\hline $\begin{array}{l}\text { Strategy for Borderline } \\
\text { Values }\end{array}$ & $100 \%(99.7-100)$ & $99.4 \%(99.2-99.6)$ & $79.7 \% / 100 \%$ \\
\hline $\begin{array}{l}\text { Strategy for Borderline } \\
\text { Values }\end{array}$ & \multicolumn{3}{|c|}{$\begin{array}{l}\text { tTG-lgA }>4 \mathrm{U} / \mathrm{mL} \text { or } \mathrm{tTG} 2-4 \mathrm{U} / \mathrm{mL} \text { with EMA-lgA } \geq 1,5 \text {, and s-lgA }<0.5 \mathrm{~g} / \mathrm{L} \text { with } \mathrm{tTG}-\lg \mathrm{g}>6 \mathrm{U} / \mathrm{mL} \text { or } 3-6 \\
\text { with EMA-lgG } \geq 1,5\end{array}$} \\
\hline
\end{tabular}

EMA, antiendomysial antibodies; dGP, deamidated gliadin peptide

Data are from ${ }^{25,158-171}$

Foods that contain 20 parts per million of gluten contain $0.002 \%$ gluten

Biocard Celiac disease, AniBiotech,Vantaa, Finland

Self-prescribed gluten-free diets may provide symptomatic relief, but when practiced prior to serologic or biopsy testing, delays the opportunity to get a firm diagnosis. ${ }^{54}$ Patients with non-celiac gluten sensitivity (NCGS) may discover that gastrointestinal symptoms improve solely with gluten avoidance, ${ }^{14}$ but there is evidence from a carefully controlled study that NCGS may actually be triggered by foods with fermentable, poorly absorbed, short-chain carbohydrates (FODMAPs). ${ }^{16}$ The abundance of sweet tasting, but poorly absorbed short-chain carbohydrates in the Western diet, such as fructooligosaccharides (fructans) and galacto-oligosaccharides (GOS), has also been shown to be a trigger for irritable bowel symptoms. Biesiekierski et al., ${ }^{16}$ placed gluten-sensitive participants on a low FODMAP diet and randomized them into one of 3 treatments: $16 \mathrm{~g} / \mathrm{d}$ whole-wheat gluten (gluten arm), $16 \mathrm{~g} / \mathrm{d}$ whey protein isolate (whey arm), or no additional protein (placebo arm) with crossover after a washout period. In the run-in period symptoms decreased significantly from their usual diet baseline. The authors reported a nocebo effect, as they were unable to detect significant differences across the treatment periods for participants with NCGS on a low FODMAP diet.

Many patients find the standard gluten challenge of 8-10 g/day for several weeks prior to serum and histological testing unmanageable. In order to evaluate the minimum gluten challenge that will result in an accurate test, 20 adults with biopsy proven CD on a GFD were challenged for two weeks with either3 or $7.5 \mathrm{mg}$ gluten/day. ${ }^{48}$ There was no significant difference between the two treatment groups and most participants met diagnostic criteria for both histology and serological testing by day 14 of the study. In a few participants there was a delayed response of IgA-tTG titer levels for 2 weeks after the challenge and well after the gastrointestinal symptoms had subsided, illustrating the need to extend the test/retest period form some patients. Leffler et al., ${ }^{48}$ concluded that the standard gluten challenge protocol could be modified with a lower gluten dose, and repeat testing for negative titers two weeks later. Published probabilities of obtaining a positive diagnosis using standard gluten challenge of 12 weeks for high risk patients is $39 \%$ and low risk symptomatic patients $3.3 \% .55$ Using data from the 2 week, modified gluten challenge supplied by Leffler, et al., ${ }^{48}$ the author of this paper calculated a post-test detection probability of only $9 \%$ for high risk, and $5 \%$ for low risk patients. Ideally, the patient should be sufficiently challenged with gluten before getting a diagnostic evaluation, and there is a wide variation in the gastrointestinal response to such a challenge.

CD and NCGS may lead to a variety of neurologic extra intestinal symptoms, such as gluten ataxia, neuropathy, epilepsy, and depressive and mood disorders. ${ }^{56-58}$ The autoimmune hypothesis for $\mathrm{CD}$ and NCGS associated neurologic disorders is supported by the presence of anti-GAD (glutamic acid decarboxylase) antibodies and antiganglioside antibodies. ${ }^{59}$ The incidence of $\mathrm{CD}$ among peripheral neuropathy patients referred to one specialty center, confirmed by elevated anti-gliadin or transglutaminase antibodies, was $2.5 \%{ }^{60}$ Gluten-related neurologic dysfunction encompasses a broad spectrum of systemic autoimmune disorders. ${ }^{61}$ 
Table 2 Potential factors influencing oral tolerance to gluten

\begin{tabular}{|c|c|c|}
\hline $\begin{array}{l}\text { Genetic and epigenetic } \\
\text { susceptibility }\end{array}$ & Environmental triggers & Immune DYsregulation \\
\hline $\begin{array}{l}\text { HLA Genotypes necessary } \\
\text { for CD, DQ2.5, DQ8 and } \\
\text { DQ2.x with a double } \\
\text { DQBI*02 } \\
\text { High Risk HLA haplotypes } \\
\text { 30\% of the general population } \\
\text { thatcarries DQ2.5/DQ8 } \\
\text { molecules do not have CD } \\
\text { and only 3\% will develop } \\
\text { NCGS } \\
\text { DQ } 2.5 \text { homozygous have } 5 \\
\text { times the risk of developing } \\
\text { CD } \\
\text { HLA-DQ types have different } \\
\text { efficiencies in presenting } \\
\text { peptides to CD4+ T cells } \\
\text { CD gene locus FRMD4B } \\
\text { (3pI4.I) } \\
\text { Myosin IXB (MYO9B) } \\
\text { genemay induce intestinal } \\
\text { permeability } \\
\text { Early postnatal development } \\
\text { affects maturation of gene- } \\
\text { specific DNA methylation, } \\
\text { producing changes in gene } \\
\text { expression }\end{array}$ & $\begin{array}{l}\text { - } \quad \text { Gene-gluten exposure } \\
\text { interaction } \\
\text { - } \quad \text { Tbesity (evidence by association) } \\
\text { Timing and exposure of gluten } \\
\text { (3-6 months, } 200 \text { mg vital wheat } \\
\text { gluten)in infants with high risk } \\
\text { genotype delays onset of CD } \\
\text { Timing of enteroviral infections } \\
\text { (rotavirus and adenovirus) } \\
\text { enhancing CD4+T-cell response } \\
\text { Dysbiosis (Gram-negative } \\
\text { bacteria and reduced } \\
\text { Bifidobacterium \& Lactobacillus) } \\
\text { Glyphosate (herbicide) disrupts } \\
\text { gut bacteria and CYP enzymes } \\
\text { in liver } \\
\text { ATls } \\
\text { FODMAPs } \\
\text { Food preservatives (glutamates, } \\
\text { benzoates, sulfites, and nitrates) }\end{array}$ & 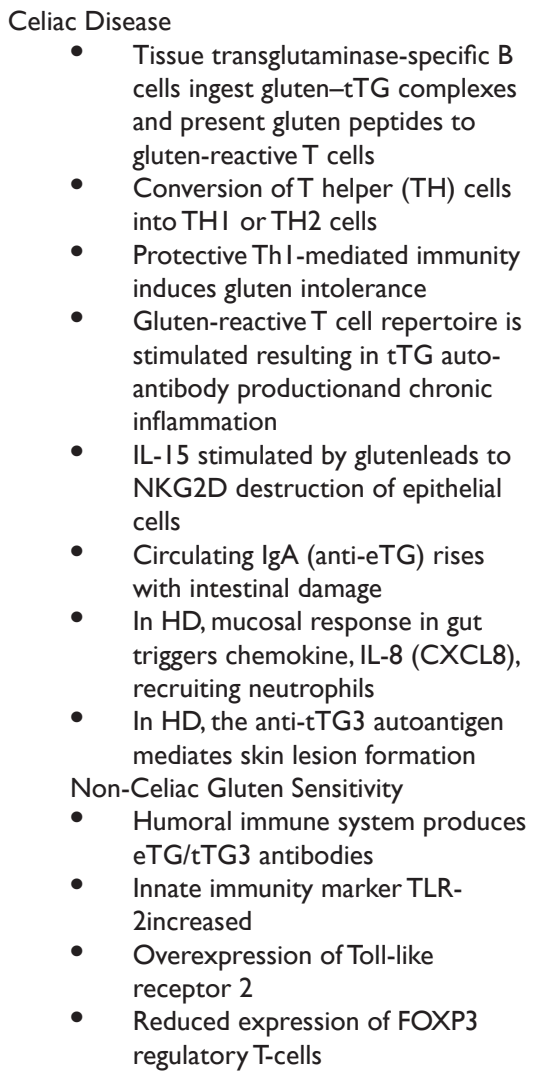 \\
\hline
\end{tabular}

CD, celiac disease; NCGS, non-celiac gluten sensitivity; HD, herpetiformis dermatitis; CD4+T-cell, $t$ helper (TH) cells express the surface protein CD4; NKG2D, natural killer group 2 ; THI, type I t helper (th I) cells;TH2, type 2 T helper (Th2) cells; myosin IXB (MYO9B), protein-coding gene; tTG, tissue transglutaminase; eTG/tTG3, epidermal transglutaminase TG3; IL I5, interleukin I5; FOXPRO3, T-regulatory cell marker

FOXP3;ATIs, amylase trypsin inhibitors; IL-8 (CXCL8), interleukin 8; IL I7 A, interleukin I7A.13,18,45, I72-188

Celiac disease is initiated by the ingestion of the protein gliadin, a component of wheat gluten, and abstinence usually resolves symptoms. For individuals with a genetic predisposition for $\mathrm{CD}, \mathrm{T}$ cell tolerance for gluten is lacking, thus triggering release of tissue transglutaminase (tTG). Gluten deamidation by tTG enhances the binding of peptides to HLA-DQ2 or HLA-DQ8 producing toxic T cell stimulatory gluten peptides. ${ }^{62}$ Both adaptive and innate immune systems are activated in CD. Recently, the role of $\alpha$-amylase/trypsin inhibitors (ATIs), molecules that function as a natural pesticide for wheat, has been shown to trigger an innate immune activation after an oral challenge. ATIs stimulate toll-like receptors (TLR4) and proinflammatory cytokines initiating an inflammatory response. ${ }^{63,64}$ Wheat, kamut, barley, rye and soy are rich sources of these molecules, while quinoa, oats, rice, and fermented soy have lower levels. ${ }^{65}$ The use of sourdough fermentation in the making of bread reduces both gluten and ATIs, and has been shown to be tolerated by subjects with CD. ${ }^{66-68}$ Because ATIs are potent nutritional TLR4 ligands, they may play a role in the etiology of NCGS and the extra intestinal effects of $\mathrm{CD}$, as well as the development of co-morbid autoimmune diseases. Verification of this hypothesis awaits the publication of ATI-free diet studies testing subjects with CD and NCGS.
Treatment for celiac disease is not complete with a diagnosis and brief patient education. On-going surveillance for dietary adherence and the development of associated conditions, such as diabetes and thyroid disorders, is necessary. If as little as 3 grams of gluten daily can trigger detectable inflammation, and $50 \mathrm{~g}$ of gluten can result in villous destruction, then testing to validate adherence has significant preventive value. Use of IgA anti-tTG rapid test is convenient in the clinical setting, and serum anti-tTG disappearance after GFD may indicate improved compliance, but not detect occasional lapses. ${ }^{69}$ The rapid test has been shown to be useful in detecting low level serologic positivity during follow-up visits $3-6$ months post- diagnosis. ${ }^{70}$ The cases discovered by the rapid test subsequently responded to intervention by a dietitian. A 5year study of adult celiac patients in France reported that IgA-tTG-ab and IgA-EMA tests were initially able to discriminate between compliant and noncompliant early in treatment, but after one year on the GFD the tests were less sensitive. ${ }^{71}$ Anovel approach to surveillance was reported by researchers in Spain who successfully tagged undigested gluten and gliadin in the feces with anti-gliadin 33-mer monoclonal antibodies. ${ }^{72}$ Healthy individuals and CD participants were placed on different levels of gluten intake and fecal samples taken. Diet intake correlated well with fecal detection. 
In a prospective study on diet compliance, patient adherence to the GFD as evaluated by a Registered Dietitian (RD) was compared to $\operatorname{IgA}$ anti-tissue transglutaminase, IgA, and IgG anti-deamidated gliadin peptides test results. ${ }^{52}$ An experienced celiac nutrition specialist determined compliance by reviewing food recall records, a comprehensive interview, and patient self-report survey, but was blinded to the results of the serological tests. Compared to serologic testing, the dietitian assessment was less accurate, but it should be noted that data was gathered long before the FDA gluten-free rules were published in 2013. A simple screening tool for primary care settings has been developed, and the 7-question Celiac Dietary Adherence Test (CDAT) was shown to be superior to serology for celiac patient follow-up. ${ }^{73}$ A group of $141 \mathrm{CD}$ patients were surveyed, and samples taken for serological and histologic evaluation. ${ }^{74}$ This short survey $(0-1=$ Non-compliant and $3-4=$ Compliant $)$ was able to predict $89.3 \%$ of the cases with villous atrophy. Celiac specialists in Germany and Australia have demonstrated in randomized, controlled studies that online diet instruction and follow-up improves the knowledge, adherence, and quality of life of newly diagnosed patients. Trials of the efficacy of CD interventions using behavioral health technology or motivational interviewing techniques are lacking in the North American celiac treatment literature.

Diet education and individual motivation were shown to be poor predictors of unintentional diet lapses caused by inaccurate food label or cross-contamination. ${ }^{75}$ For some though, non-adherence may be associated with the erroneous belief that an individual with $\mathrm{CD}$ has some level of tolerance to occasional gluten intake. This may be especially true for individuals who have a delayed response or extra intestinal symptoms. The lack of GF food labelling standards in the US may have adversely impacted those who may have silent forms of $\mathrm{CD}$, where fatigue or cognitive problems may be the only symptoms of dietary indiscretion. In a survey of US pediatricians and primary care physicians on the symptoms of $\mathrm{CD}$, only $54 \%$ were aware that chronic fatigue, and $46 \%$ knew that depression and other mood disorders were related. ${ }^{76}$

Some individuals cannot tolerate even a minute amount of gluten from their food or environment, and may have persistent symptoms and villous atrophy. These patients are classified as having nonresponsive celiac disease (NRCD), a small subgroup of $1-2 \%$ of $\mathrm{CD}$ patients with refractory disease that do not seem to heal when following the strictest of gluten restrictions. An even more restrictive approach, termed the Gluten Contamination Elimination Diet (GCED), has been shown to be effective in eliminating symptoms and promoting healing in for many patients in this group..$^{77}$ In a sample of 17 patients with presumed refractory celiac disease, $82 \%$ showed improvement on a strict regimen primarily consisting of rice, fresh meats, fruits and vegetables, dairy, and GF supplemental formulas for 3-6months. Participants were able to resume a less gluten-free regimen after a period of rehabilitation and recovery which can take 6 months to 2 years. For the patients whose symptoms persisted, one can only speculate at this point whether ATIs were the cause.

\section{Celiac management in primary care}

Little has been published in North America on the long-term treatment practices of primary care physicians and specialists. A survey of 185 US expert and non-expert gastroenterologists revealed that in 2012, before publication of ESPGHAN guidelines, there was a wide variation of practice between the two levels of expertise. ${ }^{78}$ The participants responded to questions about four celiac patient care vignettes. Experts significantly deviated from non-experts in their endorsement of screening asymptomatic patients in high-risk groups, such as Type I diabetes, relatives of the CD patient, and Downs Syndrome. There also was a significant difference in the length of pretest gluten challenge protocols ranging from 4 to 12 weeks. A cross-sectional survey of 237 Canadian gastroenterologists reported that most physicians use published practice guidelines with adult physicians following AGA, while pediatricians referred to ESPGHAN for guidance. ${ }^{79}$ Follow-up serology timeframes ranged from 3 to 9 months after initial diagnosis. Although $76 \%$ of the specialists followed patients on a long-term basis, the remainder referred patients back to the primary care setting. Specialists who rarely saw patients for a follow-up visit were more likely to believe that the surveillance was unnecessary after the patient has started a GFD, and were also less likely to review the diet with the patient at subsequent visits.

Vitamin and mineral status are infrequently monitored. At one tertiary celiac treatment center in Israel, investigators reported that follow-up with children and an adults was inadequate. ${ }^{80}$ Considering the risk for coronary artery disease, anemia, diabetes, and osteoporosis in this population, nutritional monitoring and counseling be a part of routine follow-up. ${ }^{81-83}$ In addition to serum antibodies, the annual visit should include an evaluation of BMI, bone density, $\mathrm{CBC}$, iron, folate, vitamin D, albumin, total protein, liver enzymes, PT, and electrolytes. ${ }^{84}$ Malabsorption and chronic inflammation are detrimental to calcium metabolism and it appears that compliance alone may not prevent the incidence of fractures commonly seen in individuals with $\mathrm{CD} .{ }^{82,85,86}$

\section{Quality of information in the market place}

The Nutrition Facts Label and websites sponsored by various celiac disease awareness organizations remain the most important sources of information for the person who is gluten intolerant. When 1583 celiac consumers and 797 people with gluten sensitivity were surveyed, those with $\mathrm{CD}$ were more likely to review the ingredient list prior to a food purchase than those with NCGS who selected foods primarily by their gluten-free product claims ${ }^{87}$ This is an important distinction to make because processed foods may contain unidentified sources of gluten, such as seasonings, hydrolyzed proteins and modified starches. Once the GF labeling law in the US becomes familiar to consumers, they will likely be less critical and knowledgeable of product contents because they will not have to actively seek for information on foods that are safe for them to eat. ${ }^{88}$ When asked about the quality of information from various sources, participants in Canada rated health information as excellent from the following sources: Canadian Celiac Association (64\%), gastroenterologists (28\%), dietitians (26\%) and primary care physician $(12 \%){ }^{89}$ Researchers specializing in celiac treatment in the United States were interested in the quality of information available on the Internet. They rated the accuracy, comprehensiveness, transparency, and readability of consumer information from a sample of English language, US-based information Internet sites. ${ }^{90}$ The sample of 98 sites was drawn from various academic, commercial, nonprofit, or non-academic professional organizations. When the weighted cumulative average was summed into a composite score of the component indicators, only 4 of the 98 sites achieved a score of 8 , which was the minimum for a quality website. Of the sites that met their criteria, an academic, a commercial site and two non-profits made the cut.

Consumers ultimately are the final arbiters of information that helps them with their celiac diet and general wellness. An ethnographic study of celiac online discussion boards and support 
groups reported that consumers rely increasingly on alternate ways of getting health information, from home celiac testing kits to gluten-free diet information from the media. ${ }^{54}$ From the conversational analysis from an online discussion board, the authors suggest that the long "path" to the diagnosis may be a promoter of diet non-compliance behaviors. Many adults who are newly diagnosed have been through years of frustration due to disappointing negative test results in spite of on-going GI symptoms. A national survey of Canadians with CD reported nearly one-third $(27 \%)$ had consulted 3 or more physicians before finally getting a definitive diagnosis. ${ }^{91}$ Because of this delay, the health care team may in fact be perceived as less trustworthy compared to other information sources.

\section{Access to medical nutrition therapy}

Although AGA guidelines support providing an ongoing follow-up by an $\mathrm{RD}$, most American patients see a dietitian once if at all in the initial period after the biopsy confirmation..$^{92,93}$ Access to a dietitian does not insure that the services are from a competent nutrition counselor trained to provide both celiac diet education and counseling for eating disorder management as most nutrition specialists tend to work in medical school based celiac treatment centers rather than at the community level. ${ }^{94-96}$ Innovative approaches to service delivery for on-going services such as a dietitian-led clinic, virtual clinic, and in the medical home setting are ways to make nutrition counseling more accessible to the general celiac population. ${ }^{96-98}$ Gluten-intolerant individuals will seek out other complementary treatment when their well-being does not improve. In a survey of German celiac patients with IBS-like symptoms had higher rates of health seeking behavior such as acupuncture, medications, and psychotherapy, especially if they also had co-morbidities. ${ }^{99}$ Of the symptomatic individuals, $32.3 \%$ reported following their GFD "most of the time." An annual multidisciplinary evaluation may help to bridge the trust divide.

Daily management of the GFD is frequently challenging, especially when eating at restaurants or traveling. The individual with $C D$ lives with the threat of being accidently "glutened". Within an online forum at Celiac.com, researchers analyzed the conversations of a single-case subject who announced the desire to quit the diet in a forum posting. ${ }^{100}$ This declaration prompted other posters to express their feelings and strategies for sticking with the diet. The diet faithful and the less adherent expressed their feelings toward dietary transgressions, and ultimately shared supportive measures to manage everyday health risk. The authors concluded that diet adherence should be best approached as a "collective phenomenon" not as the achievement of one individual. Virtual or face-to-face support group in helping patients deal with the social challenges unique to the GFD. ${ }^{93,101}$ Due to the difficulty of maintaining a gluten-free home when other household members do not have the disorder, websites are available to match single people who share the same gluten-free lifestyle. ${ }^{102}$ Healthcare researchers should begin to explore the uses and gratifications of social health media use, such as online health gaming to support better diet adherence and wellness which has been effective for diabetes self-management and other chronic diseases. ${ }^{103-107}$ Mobile health applications and smart phone apps are being successfully marketed to assist celiac patients in food shopping, and locating celiac-friendly restaurants. ${ }^{108}$

\section{Intervention studies}

Research from dietitians working with adult-onset CD in the US is rarely published, but personally and professionally I am aware of many who belong to a specialty GI practice group sponsored by the
Academy of Nutrition and Dietetics. Researchers from the Columbia University Celiac Center surveyed celiac patients at their clinic, and attendees at conferences in Iowa, California, and New York. Survey results failed to show an association between consultation with a dietitian and CD-quality of life, celiac diet adherence test (CDAT), or celiac symptom index (CSI) upon univariate analysis. ${ }^{93}$ It is not clear from this study how counseling method or treatment setting may play a part in the effectiveness of the intervention. Access to a dietitian trained in celiac diagnosis and treatment has been identified as important to celiac patients. ${ }^{109}$ To meet the specialty training needs for health professionals the University of Chicago Celiac Disease Center's Preceptor ship Program hosts an intensive, 2-day training course for medical and allied health professionals. Future studies should identify the effectiveness of interventions outside of the clinic setting, such as telephonic or web-based health coaching, point-ofpurchase tours led by a Registered Dietitians, home visit, or worksite wellness programs.

A growing international concern is the association of $\mathrm{CD}$ with obesity, as reported in studies in Ireland/UK and the US. ${ }^{110-112}$ On the other hand, the prevalence of obesity among newly diagnosed patients was significantly lower in a large Massachusetts sample compared to the general population ( $32 \%$ vs. $59 \%, \mathrm{P}<0.0001)$, but this study also identified a trend toward weight gain in normal and overweight participants by the 2year follow-up. ${ }^{113} \mathrm{~A}$ diet intervention study for newly-diagnosed normal and overweight patients may give us more understanding of the risk for obesity in this population. A correlational study in the United States tracked weight change after the initial diagnosis and observed that the GFD was beneficial for weight management, unfortunately there was no specific protocol, the topic was simply "addressed" in the normal nutrition follow-up visit. ${ }^{114}$

Co-morbidities associated with $\mathrm{CD}$, such as diabetes, osteoporosis, and heart disease, increase the complexity of wellness interventions. Recently, researchers at Cleveland clinic analyzing electronic medical records at several hospitals reported an odds ratio of 2.0 (95\% CI 1.8 to 2.1) of coronary artery disease among patients with $\mathrm{CD}$ compared to the control patient population. Newly diagnosed CD patients when compared to age and gender matched controls, were almost 7 times more likely to have osteoporosis (adjusted OR 6.9, 95\% CI 0.7-65, $\mathrm{P}<0.093$ ). ${ }^{115}$ Lifestyle intervention for $\mathrm{CD}$ beyond the gluten-free diet should include a heart healthy diet, physical activity, and appropriate nutritional supplements. ${ }^{16-119}$

Dietary management at the time of diagnosis and at regular intervals a was shown to be effective for pediatric celiac patients with Type 1 Diabetes Mellitus with improvement in glucose control, GI symptoms, weight, and bone density. ${ }^{120}$ Children with $\mathrm{CD}$ are especially vulnerable to secondary effects of celiac disease. Entrepreneurs are now offering home delivery of gluten-free, portion controlled, and low sugar or sodium meals to meet the needs of glutenfree consumers who are managing co-morbid conditions.

\section{Gluten-free is not enough}

Unlike Canada, fortification of gluten-free grain products remains voluntary in the US, Europe, and Australia. A study of newly diagnosed patients with $\mathrm{CD}$ in Australia, reported that after oneyear participants diets frequently fell short of recommended intakes for thiamin, folate, vitamin A, magnesium, calcium, fiber, and iron. ${ }^{121} \mathrm{An}$ Italian study observed that patients on a GFD ate an unbalanced diet favoring saturated fats from eggs, meat and cheese and reduced their consumption of dietary carbohydrates from their previous pattern. ${ }^{122}$ 
Reliance on meat, highly-processed grains, saturated fats, highsodium foods, and sugary beverages are becoming the norm in most industrialized countries, including those who previously consumed a Mediterranean traditional foods diet. A tenyear study of celiac patients showed a significantly higher plasma homocysteine levels compared to general population which corresponded to the low folate and B12 serum levels in half of the participants. ${ }^{123}$ Cross-sectional data from Italy and Israel suggest that children are clearly at risk as well, as the rate of having a borderline LDL value doubled after diet adherence, and unhealthy weight gain followed maintenance on a GFD. ${ }^{124}$ Celiac patients who follow a gluten-free, heart healthy diet may reduce their risk of cardiovascular disease. Results of a diet survey study in the US raised concerns that less than half of the participants on a GFD did not get the recommended dietary intake for whole grains, calcium, iron, and fiber. ${ }^{125}$ Death from ischemic heart disease has been estimated at 1.22 times the general population $(95 \% \mathrm{CI}, 1.06$ to $1.40, \mathrm{p}<.05)$ in a nationwide study in Sweden. ${ }^{126}$ A 5year study of women with $\mathrm{CD}$ in Southern Italy showed that bone density improves the longer a participant was on the GFD, but failed to detect a relationship between levels of physical activity and bone density. ${ }^{127}$ In fact, more than half of the women had low levels of physical activity, reportedly due to chronic fatigue. Because anemia is a frequent symptom in the newly diagnosed or non-adherent patient, iron enrichment of GF breads and cereals would be a welcome preventive measure. The addition of iron to GF bread products does not reduce their quality and palatability. ${ }^{128}$ Introduction of $\mathrm{GF}$ products with added vitamin $\mathrm{D}$, vitamin $\mathrm{K}$, B6,B12, methylated folate (5-MTHF), and calcium, zinc, selenium, and copper would help the gluten-intolerant recover from villous atrophy, and prevent celiac related nutrient deficiencies.

A consequence of the GFD is that it alters the gut microbiome by favoring the pro-inflammatory species of bacteria and fungi. ${ }^{129,130}$ Once the GF diet is initiated, changes in diversity and composition of the intestinal microbiota favor a reduction in Lactobacillus and Bifidobacterium species. ${ }^{131,132}$ This effects mucosal healing because gluten is degraded by these microorganisms thus preventing its uptake into the mucosa ultimately reducing immune activation. ${ }^{133,134}$ The development and use of targeted probiotic therapy will likely be commonplace in a fewyears as an effort to preserve mucosal integrity, but at this point the efficacy of probiotic supplements nor enriched probiotic food products has not been demonstrated in CD. ${ }^{133-135}$ Because many people with celiac and other inflammatory GI diseases are lactose deficient, the inclusion of fermented milk products rich in Lactobacillus and Bifidobacterium may create a healthier balance of species in the gut microbiome, while allowing a tolerant form of these nutritious foods to be included in the diet.

The long-term nutritional and health risks of this disease require ongoing surveillance for diet adherence, bone density, anemia, body mass index, vitamin $\mathrm{D}$, and cardiovascular risk. The savings from the team management by a gastroenterologist, primary care physician, and celiac expert dietitian can only be speculated at this point, but there is some data to suggest that the utilization of health services is lower after diagnosis and treatment. ${ }^{136}$ Considering the various risk factors in CD patients, comprehensive celiac care should include a cardiovascular risk management program in addition to the GFD.

\section{Safety of food and pharmaceutical products}

Wheat starch based, gluten-reduced products are widely available in Europe, but have not been marketed in the US. As of August 2014, the FDA will allow foods with a grain ingredient that has been processed to remove gluten and containing less than $20 \mathrm{ppm}$ (parts per million) in the final product. ${ }^{137}$ Gluten is not only found in food, but significant amounts are found in medications, beverages, and cosmetics. ${ }^{138,139}$ Many alcoholic beverages make gluten-free claims and this is regulated by the Department of the Treasury, Alcohol and Tobacco Tax and Trade Bureau (TTB). The TTB issued an interim policy pending determination by the FDA for the testing of beverages that are processed to remove gluten due to a lack of recognized standards and methodologies for alcoholic beverages produced from grains. ${ }^{140}$ Many of these products are currently allowed to use the term "gluten-free" on labels and in marketing if the product would also be entitled to make a gluten-free label claim under the standards set forth in the new FDA regulations at 21 CFR 101.9. ${ }^{137,141}$ Crosscontamination in the production and processing of naturally occurring gluten-free foods are more common than previously thought. ${ }^{142-144}$ Currently, drug manufacturers supply information on their products on a voluntary basis. ${ }^{145}$ Due to the possibility of gluten contamination in most manufacturing facilities, only tested gluten-free products and medications should be deemed safe. Prior to the new FDA gluten-free rules, researchers tested a small sample of gluten-free and "certified" gluten-free off-the-shelf food products $(\mathrm{n}=158)$ using an appropriate R5enzyme-linked immunosorbent assay (ELISA), sandwich or competitive methods, by a third-party allergen test lab. ${ }^{146}$ Results indicated that although most products contained less than 20ppm, nearly $5 \%$ contained more than the allowable limit. But since the procedure for gluten testing is at the discretion of the manufacturer, it is not known if each batch of final product is tested.

For many gluten-intolerant individuals they experience a cycle of gluten triggered endothelial attacks that result in a state of chronic low level inflammation, even with the best of dietary compliance efforts in an untested marketplace. Oxidative stress in the cell is stimulated by the uptake of $\alpha$-gliadin peptides into the lysosomes triggering release of reactive oxidative species (ROS) ${ }^{147}$ ROS are involved in the reduced degradation of tTG resulting in elevated tTG protein levels. The reduction in oxidative defense mechanisms in CD further increases tissue susceptibility to damage. In two small studies, CD patients were given a wheat-based sourdough bread produced with lactobacilli in a two day trial did not increase intestinal permeability, and in another study consumption of this bread promoted intestinal recovery by reducing the release of nitrous oxide. ${ }^{67,68} \mathrm{In} \mathrm{CD}$ the release of arachidonic acid from intra-epithelial lymphocytes promotes intestinal inflammation, and there is some data to suggest that docosahexaenoic acid (DHA) supplementation may counter this effect. ${ }^{148}$ The antioxidant vitamins, polyphenols, carotenoids, lycopene, and quercetin have been shown to inhibit the generation of oxidative species. ${ }^{149-151}$ Clinical trials should include subjects from the celiac disease population to establish the effects of nutrition supplements on chronic inflammation. Because of the association of $\mathrm{CD}$ with other chronic diseases, such as diabetes, and cardiovascular disease, the development of new gluten-free foods should be focused on nutritional balance for the prevention of chronic disease, not merely focused on sensory quality and convenience. Gluten-free foods and beverages that are enriched with probiotics, fiber, calcium, iron, $\mathrm{n}^{-3}$ fatty acids, and vitamins should be developed for this growing market. The use of products made with resistant starches that offer low glycemic indices would be beneficial for individuals with diabetes. ${ }^{152}$

Depending on the country, the standard threshold for glutenfree can be as low as $20 \mathrm{ppm}$ and as high as $200 \mathrm{ppm} .{ }^{153}$ In reality, a safety margin depends on an individual's tolerance which varies according to gut mucosal integrity, balance of duodenal microbiota, and the presence of infection. ${ }^{154}$ Patients challenged with small 
amounts of gluten in a multi-center, placebo-controlled, double-blind, randomized trial, experienced histological changes given $50 \mathrm{mg}$ gluten/d or $10 \mathrm{mg}$ gluten. ${ }^{155}$ The median villous ratio $(\mathrm{Vh} / \mathrm{Cd})$ in the $\mathrm{CD}$ group was significantly different from controls $(\mathrm{Mdn}=2.20 ; 95 \%$ C.I. [2.11, 2.89], $\mathrm{p}=.019)$. A systematic review of the literature found little quality evidence that would support the Codex standard of 200 ppm for "safe" levels of consumption. ${ }^{156}$

\section{Discussion}

The availability of GF labeled products makes it easier than ever before to maintain a gluten-free lifestyle. The likelihood that a person with $\mathrm{CD}$ will adhere to their diet depends on four factors: availability of gluten-free foods, taste preference, knowledge, and social support. For the self-diagnosed gluten sensitive person, we do not have a clear understanding of the uses and gratifications associated with this diet. For some individuals the need for this diet may be related to cognitive problems, irritable bowel syndrome, dysbiosis, and overconsumption of FODMAPs. For others, gluten sensitivity may be due to celiac disease in a latent form. Because the wellness literature has paid limited attention to celiac disease, there are gaps in our knowledge of factors that promote and sustain wellness. The fatigue reported by many with celiac disease can lead to lower levels of fitness and a higher risk of diabetes and cardiovascular disease. Physical activity to build and maintain bone mass and endurance should be promoted as part of a healthy celiac lifestyle. ${ }^{127,157}$ There are many opportunities for research on factors that enhance physical activity and nutritional status for gluten intolerant individuals. Future research should evaluate and disseminate best health intervention practices for the identification and treatment of patients with gluten sensitivities.

\section{Conclusion}

There are gaps in our knowledge about the effectiveness of public health marketing, social media, worksite wellness programs, and point-of-purchase information for individuals with gluten sensitivity. Developing marketplace solutions for the health needs of people with $\mathrm{CD}$ and gluten-sensitivity through the development of webbased health technologies certified functional GF foods, retail health professional guidance, and physical fitness interventions to promote bone density, healthy weight, and endurance will result in life-long health for the gluten intolerant.

\section{Acknowledgements}

I would like to thank the researchers that I "follow" on the Research Gate networking site for their generosity of giving me access to various new publications. These include Drs. Drossman, Fasano, Leffler, and Murray.

\section{Conflict of interest}

This paper received no grant support from any funding agency in the public, commercial, or not-for-profit sectors. The author may apply for open access publication fees from the University of Connecticut. I certify that, to the best of my knowledge, no aspect of my current personal or professional circumstances place me in the position of having a conflict of interest. In the interest of full disclosure, I would like to declare that I have herpetiformis dermatitis.

\section{References}

1. Husby S, Murray JA. Defining thresholds of antibody levels improves diagnosis of celiac disease: replacing the gold standard. Clin Gastroenterol Hepatol. 2013;11(4):404-405.
2. Husby S, Koletzko S, Korponay-Szabo IR, et al. European Society for Pediatric Gastroenterology, Hepatology, and Nutrition guidelines for the diagnosis of coeliac disease. J Pediatr Gastroenterol Nutr. 2012;54(1):136-160.

3. Rostom A, Murray JA, Kagnoff MF. American Gastroenterological Association (AGA) Institute Technical Review on the Diagnosis and Management of Celiac Disease. Gastroenterology. 2006;131(6): 1981-2002.

4. Catassi C, Gatti S, Fasano A. The new epidemiology of celiac disease. $J$ Pediatr Gastroenterol Nutr. 2014;59(Suppl 1):S7-S9.

5. Mustalahti K, Catassi C, Reunanen A, et al. The prevalence of celiac disease in Europe: results of a centralized, international mass screening project. Ann Med. 2010;42(8):587-595.

6. Makharia GK, Catassi C, Goh KL, et al. Celiac disease. Gastroenterol Res Pract. 2012;2012:758560.

7. Kochhar R, Sachdev S, Aggarwal A, et al. Prevalence of coeliac disease in healthy blood donors: A study from north India. Dig Liver Dis. 2012;44(6):530-532.

8. Rajpoot P, Makharia GK. Problems and challenges to adaptation of gluten free diet by Indian patients with celiac disease. Nutrients. 2013;5(12):4869-4879.

9. Kang JY, Kang AH, Green A, et al. Systematic review: worldwide variation in the frequency of coeliac disease and changes over time. Aliment Pharmacol Ther. 2013;38(3):226-245.

10. Green PH. The many faces of celiac disease: Clinical presentation of celiac disease in the adult population. Gastroenterology. 2005;128(4 Suppl 1):S74-S78.

11. Oliveira A, Trindade E, Tavares M, et al. Celiac disease in first degree relatives of celiac children. Arq Gastroenterol. 2012;49(3):204-207.

12. Sperandeo MP, Tosco A, Izzo V, et al. Potential celiac patients: a model of celiac disease pathogenesis. PLoS One. 2011;6(7):e21281.

13. Lundin KE, Alaedini A. Non-celiac gluten sensitivity. Gastrointest Endosc Clin N Am. 2012;22(4):723-734.

14. Biesiekierski JR, Newnham ED, Irving PM, et al. Gluten causes gastrointestinal symptoms in subjects without celiac disease: a doubleblind randomized placebo-controlled trial. Am J Gastroenterol. 2011;106(3):508-514.

15. Volta U, Caio G, Tovoli F, et al. Non-celiac gluten sensitivity: questions still to be answered despite increasing awareness. Cell Mol Immunol. 2013;10(5):383-392.

16. Biesiekierski J, Peters SL, Newnham E, et al. No effects of gluten in patients with self-reported non-celiac gluten sensitivity following dietary reduction of low-fermentable, poorly-absorbed, short-chain carbohydrates. Gastroenterology. 2013;145(2):320-328.

17. Hadjivassiliou M, Sanders DS, Grunewald RA, et al. Gluten sensitivity: from gut to brain. Lancet Neurol. 2010;9(3):318-330.

18. DiGiacomo DV, Tennyson CA, Green PH, et al. Prevalence of glutenfree diet adherence among individuals without celiac disease in the USA: results from the Continuous National Health and Nutrition Examination Survey 2009-2010. Scand J Gastroenterol. 2013;48(8):921-925.

19. Inomata N. Wheat allergy. Curr Opin Allergy Clin Immunol. 2009;9(3):238-243.

20. Gordins P, McLean-Tooke A, Spickett GP. The role of omega-5 gliadinspecific IgE test in diagnosing exercise-induced wheat allergy. Int Arch Allergy Immunol. 2011;155(1):93-94.

21. Brisman J. Baker's asthma. Occup Environ Med. 2002;59(7):498-502.

22. Castells MC, Horan RF, Sheffer AL. Exercise-induced anaphylaxis. Curr Allergy Asthma Rep. 2003;3(1):15-21. 
23. Waga J, Obtulowicz K, Zientarski J, et al. Purified wheat gliadin proteins as immunoglobulin $\mathrm{E}$ binding factors in wheat mediated allergies. American Journal of Plant Sciences. 2011;2(3):476-483.

24. Husby S, Koletzko S, Korponay-Szabo IR, et al. European Society for Pediatric Gastroenterology, Hepatology, and Nutrition guidelines for the diagnosis of coeliac disease. $J$ Pediatr Gastroenterol Nutr. 2012;54(1):136-160.

25. Giersiepen K, Lelgemann M, Stuhldreher N, et al. Accuracy of diagnostic antibody tests for coeliac disease in children: summary of an evidence report. J Pediatr Gastroenterol Nutr. 2012;54(2):229-241.

26. Villalta D, Alessio MG, Tampoia M, et al. Diagnostic accuracy of IgA anti-tissue transglutaminase antibody assays in celiac disease patients with selective IgA deficiency. Ann N Y Acad Sci. 2007;1109:212-220.

27. Taavela J, Kurppa K, Collin P, et al. Degree of damage to the small bowel and serum antibody titers correlate with clinical presentation of patients with celiac disease. Clin Gastroenterol Hepatol. 2013;11(2):166-171.

28. Bednarska O, Ignatova S, Dahle C, et al. Intraepithelial lymphocyte distribution differs between the bulb and the second part of duodenum. BMC Gastroenterol. 2013;13:111.

29. Ravelli A, Villanacci V, Monfredini C, et al. How patchy is patchy villous atrophy?: distribution pattern of histological lesions in the duodenum of children with celiac disease. Am $J$ Gastroenterol. 2010;105(9):2103-2110.

30. Ravelli A, Villanacci V. Tricks of the trade: How to avoid histological pitfalls in celiac disease. Pathol Res Pract. 2012;208(4):197-202.

31. Wolf J, Hasenclever D, Petroff D, et al. Antibodies in the diagnosis of coeliac disease: a biopsy-controlled, international, multicentre study of 376 children with coeliac disease and 695 controls. PLoS One. 2014;9(5):e97853.

32. Ludvigsson JF, Rubio-Tapia A, van Dyke CT, et al. Increasing incidence of celiac disease in a North American population. Am J Gastroenterol. 2013;108(5):818-824.

33. Catassi C, Fasano A. Celiac disease diagnosis: simple rules are better than complicated algorithms. Am J Med. 2010;123(8):691-693 .

34. Catassi C, Kryszak D, Louis-Jacques O, et al. Detection of Celiac disease in primary care: a multicenter case-finding study in North America. Am J Gastroenterol. 2007;102(7):1454-1460.

35. Shirts BH, Bennett ST, Jackson BR. Using patients like my patient for clinical decision support: institution-specific probability of celiac disease diagnosis using simplified near-neighbor classification. $J$ Gen Intern Med. 2013;28(12):1565-1572.

36. Bonciani D, Verdelli A, Bonciolini V, et al. Dermatitis herpetiformis: from the genetics to the development of skin lesions. Clin Dev Immunol. 2012;2012:239691.

37. Karpati S. An exception within the group of autoimmune blistering diseases: dermatitis herpetiformis, the gluten-sensitive dermopathy. Immunol Allergy Clin North Am. 2012;32(2):255-262.

38. Troncone R, Discepolo V. Celiac disease and autoimmunity. J Pediatr Gastroenterol Nutr. 2014;59(Suppl 1):S9-S11.

39. Plotnikova N, Miller JL. Dermatitis herpetiformis. Skin Therapy Lett. $2013 ; 18(3): 1-3$.

40. Paek SY, Steinberg SM, Katz SI. Remission in dermatitis herpetiformis: a cohort study. Arch Dermatol. 2011;147(3):301-305.

41. Garioch JJ, Lewis HM, Sargent SA, et al. 25 years' experience of a gluten-free diet in the treatment of dermatitis herpetiformis. $\mathrm{Br} \mathrm{J}$ Dermatol. 1994;131(4):541-545.

42. Garner C, Ahn R, Ding YC, et al. Genome-wide association study of celiac disease in north america confirms FRMD4B as new celiac locus. PLoS One. 2014;9(7):e101428.
43. Harpsoe MC, Basit S, Andersson M, et al. Body mass index and risk of autoimmune diseases: a study within the Danish National Birth Cohort. Int J Epidemiol. 2014;43(3):843-855.

44. Lebwohl B, Granath F, Ekbom A, et al. Mucosal healing and mortality in coeliac disease. Aliment Pharmacol Ther. 2013;37(3):332-339.

45. Wolters VM, Verbeek WH, Zhernakova A, et al. The MYO9B gene is a strong risk factor for developing refractory celiac disease. Clin Gastroenterol Hepatol. 2007;5(12):1399-1405.

46. Rubio-Tapia A, Ludvigsson JF, Brantner TL, et al. The prevalence of celiac disease in the United States. Am $J$ Gastroenterol. 2012;107(10):1538-1544.

47. Aziz I, Lewis NR, Hadjivassiliou M, Winfield SN, et al. A UK study assessing the population prevalence of self-reported gluten sensitivity and referral characteristics to secondary care. Eur $J$ Gastroenterol Hepatol. 2014;26(1):33-39.

48. Leffler D, Schuppan D, Pallav K, et al. Kinetics of the histological, serological and symptomatic responses to gluten challenge in adults with coeliac disease. Gut. 2013;62(7):996-1004.

49. Biesiekierski JR, Newnham ED, Shepherd SJ, et al. Characterization of adults with a self-diagnosis of nonceliac gluten sensitivity. Nutr Clin Pract. 2014;29(4):504-509.

50. Kabbani TA, Vanga RR, Leffler DA, et al. Celiac disease or non-celiac gluten sensitivity? An approach to clinical differential diagnosis. Am J Gastroenterol. 2014;109(5):741-746.

51. Volta U, Bardella MT, Calabro A, et al. An Italian prospective multicenter survey on patients suspected of having non-celiac gluten sensitivity. BMC Med. 2014;12:85.

52. Leffler DA, Edwards George JB, Dennis M, et al. A prospective comparative study of five measures of gluten-free diet adherence in adults with coeliac disease. Aliment Pharmacol Ther. 2007;26(9):1227-1235.

53. Zanini B, Lanzarotto F, Mora A, et al. Five year time course of celiac disease serology during gluten free diet: results of a community based “CD-Watch” program. Dig Liver Dis. 2010;42(12):865-870.

54. Copelton DA, Valle G. "You don't need a prescription to go glutenfree": the scientific self-diagnosis of celiac disease. Soc Sci Med. 2009;69(4):623-631.

55. Sugai E, Moreno ML, Hwang HJ, et al. Celiac disease serology in patients with different pretest probabilities: is biopsy avoidable? World $J$ Gastroenterol. 2010;16(25):3144-3152.

56. Cicarelli G, Della Rocca G, Amboni M, et al. Clinical and neurological abnormalities in adult celiac disease. Neurol Sci. 2003;24(5):311-317.

57. Vaknin A, Eliakim R, Ackerman Z, et al. Neurological abnormalities associated with celiac disease. J Neurol. 2004;251(11):1393-1397.

58. Boscolo S, Sarich A, Lorenzon A, et al. Gluten ataxia: passive transfer in a mouse model. Ann N Y Acad Sci. 2007;1107:319-328.

59. Jackson JR, Eaton WW, Cascella NG, et al. Neurologic and psychiatric manifestations of celiac disease and gluten sensitivity. Psychiatr $Q$. 2012;83(1):91-102.

60. Hadjivassiliou M, Sanders DS, Grunewald RA, et al. Gluten sensitivity: from gut to brain. Lancet Neurol. 2010;9(3):318-330.

61. Hadjivassiliou M, Duker AP, Sanders DS. Gluten-related neurologic dysfunction. In: B. Jose, MF Jose, editors. Neurologic Aspects of Systemic Disease Part II E-BOOK. Volume 120. Elsevier: Burlington; 2014. p. 607-619.

62. Jabri B, Sollid LM. Mechanisms of disease: immunopathogenesis of celiac disease. Nat Clin Pract Gastroenterol Hepatol. 2006;3(9):516-525.

63. Junker Y, Zeissig S, Kim SJ, et al. Wheat amylase trypsin inhibitors drive intestinal inflammation via activation of toll-like receptor 4. J Exp Med. 2012;209(13):2395-2408. 
64. Tilg H, Koch R, Moschen AR. Proinflammatory wheat attacks on the intestine: alpha-amylase trypsin inhibitors as new players. Gastroenterology. 2013;144(7):1561-1564.

65. Zevallos VF, Junker Y, Hebich B, et al. Isolation of alpha-amylase trypsin inhibitors from various plants and their ability to activate innate immunity in celiac disease. Gastroenterology. 2012;142(5 Suppl 1):S269.

66. Wolter A, Hager AS, Zannini E, et al. Influence of sourdough on in vitro starch digestibility and predicted glycemic indices of gluten-free breads. Food Funct. 2014;5(3):564-572.

67. Calasso M, Vincentini O, Valitutti F, et al. The sourdough fermentation may enhance the recovery from intestinal inflammation of coeliac patients at the early stage of the gluten-free diet. Eur J Nutr. 2012;51(4):507-512.

68. Di Cagno R, De Angelis M, Auricchio S, et al. Sourdough bread made from wheat and nontoxic flours and started with selected lactobacilli is tolerated in celiac sprue patients. Appl Environ Microbiol. 2004;70(2):1088-1096.

69. Zanchi C, Ventura A, Martelossi S, et al. Rapid anti-transglutaminase assay and patient interview for monitoring dietary compliance in celiac disease. Scand J Gastroenterol. 2013;48(6):764-766.

70. Korponay-Szabo IR, Raivio T, Laurila K, et al. Coeliac disease case finding and diet monitoring by point-of-care testing. Aliment Pharmacol Ther. 2005;22(8):729-737.

71. Vahedi K, Mascart F, Mary JY, et al. Reliability of antitransglutaminase antibodies as predictors of gluten-free diet compliance in adult celiac disease. Am J Gastroenterol. 2003;98(5):1079-1087.

72. Comino I, Real A, Vivas S, et al. Monitoring of gluten-free die compliance in celiac patients by assessment of gliadin 33-mer equivalent epitopes in feces. Am J Clin Nutr. 2012;95(3):670-677.

73. Leffler DA, Dennis M, Edwards George JB, et al. A simple validated gluten-free diet adherence survey for adults with celiac disease. Clin Gastroenterol Hepatol. 2009;7(5):530-536.

74. Biagi F, Bianchi PI, Marchese A, et al. A score that verifies adherence to a gluten-free diet: a cross-sectional, multicentre validation in real clinical life. Br J Nutr. 2012;108(10):1884-1888.

75. Hall NJ, Rubin GP, Charnock A. Intentional and inadvertent nonadherence in adult coeliac disease. A cross-sectional survey. Appetite. 2013;68:56-62.

76. Zipser RD, Farid M, Baisch D, et al. Physician awareness of celiac disease a need for further education. J Gen Intern Med. 2005;20(7):644-646.

77. Hollon JR, Cureton PA, Martin ML, et al. Trace gluten contamination may play a role in mucosal and clinical recovery in a subgroup of dietadherent non-responsive celiac disease patients. BMC Gastroenterol. 2013;13:40.

78. Parakkal D, Du H, Semer R, et al. Do gastroenterologists adhere to diagnostic and treatment guidelines for celiac disease? J Clin Gastroenterol. 2012;46(2):e12-e20.

79. Silvester J, Rashid M. Long-term management of patients with celiac disease: Current practices of gastroenterologists in Canada. Can J Gastroenterol. 2010;24(8):499-509.

80. Mozer-Glassberg Y, Zevit N, Rosenbach Y, et al. Follow-up of children with celiac disease - lost in translation? Digestion. 2011;83(4):283-287.

81. Kupper C. Dietary guidelines and implementation for celiac disease. Gastroenterology. 2005;128(4 Suppl 1):S121-S127.

82. Fouda MA, Khan AA, Sultan MS, et al. Evaluation and management of skeletal health in celiac disease: position statement. Can J Gastroenterol. 2012;26(11):819-829.
83. Haines ML, Anderson RP, Gibson PR. Systematic review: The evidence base for long-term management of coeliac disease. Aliment Pharmacol Ther. 2008;28(9):1042-1066.

84. Pietzak MM. Follow-up of patients with celiac disease: achieving compliance with treatment. Gastroenterology. 2005;128(4 Suppl 1):S135-S141.

85. Krupa-Kozak U. Pathologic bone alterations in celiac disease: Etiology, epidemiology, and treatment. Nutrition. 2014;30(1):16-24.

86. Mager DR, Qiao J, Turner J. Vitamin D and K status influences bone mineral density and bone accrual in children and adolescents with celiac disease. Eur J Clin Nutr. 2012;66(4):488-495.

87. Verrill L, Zhang Y, Kane R. Food label usage and reported difficulty with following a gluten-free diet among individuals in the USA with coeliac disease and those with noncoeliac gluten sensitivity. J Hum Nutr Diet. 2013;26(5):479-487.

88. Worosz MR, Wilson NLW. A cautionary tale of purity, labeling and product literacy in the gluten-free market. $J$ Consum Aff. 2012;46(2):288-318.

89. Zarkadas M, Cranney A, Case S, et al. The impact of a gluten-free diet on adults with coeliac disease: results of a national survey. J Hum Nutr Diet. 2006;19(1):41-49.

90. McNally SL, Donohue MC, Newton KP, et al. Can consumers trust webbased information about celiac disease? Accuracy, comprehensiveness, transparency, and readability of information on the internet. Interact $J$ Med Res. 2012;1(1):e1.

91. Cranney A, Zarkadas M, Graham ID, et al. The canadian celiac health survey. Dig Dis Sci. 2007;52(4):1087-1095.

92. Rubio-Tapia A, Hill ID, Kelly CP, et al. ACG clinical guidelines: diagnosis and management of celiac disease. Am J Gastroenterol. 2013;108(5):656-676.

93. Mahadev S, Simpson S, Lebwohl B, et al. Is dietitian use associated with celiac disease outcomes? Nutrients. 2013;5(5):1585-1594.

94. Arigo D, Anskis AM, Smyth JM. Psychiatric comorbidities in women with celiac disease. Chronic Illn. 2012;8(1):45-55.

95. Quick VM, McWilliams R, Byrd-Bredbenner C. Case-control study of disturbed eating behaviors and related psychographic characteristics in young adults with and without diet-related chronic health conditions. Eat Behav. 2012;13(3):207-213.

96. Wylie C, GS, Winwood P. Dietitian-led Coeliac Clinic: A successful change in working practice in modern healthcare. Gastroenterology Today. 2005;15(1):11-12.

97. James SA, Mead RJ, Smith T. Coeliac disease: the virtual clinic approach. Gastrointestinal Nursing. 2013;9(8):30-36.

98. Flesher M, Kinloch K, Grenon E, et al. Access to dietitians in primary health care. Can J Diet Pract Res. 2011;72(1):32-36.

99. Hauser W, Musial F, Caspary WF, et al. Predictors of irritable boweltype symptoms and healthcare-seeking behavior among adults with celiac disease. Psychosom Med. 2007;69(4):370-376.

100. Veen M, te Molder H, Gremmen B, et al. Quitting is not an option: An analysis of online diet talk between celiac disease patients. Health (London). 2010;14(1):23-40.

101. Addolorato G, De Lorenzi G, Abenavoli L, et al. Psychological support counselling improves gluten-free diet compliance in coeliac patients with affective disorders. Aliment Pharmacol Ther. 2004;20(7):777-782.

102. New Online Dating Site Launches for Gluten-Free Singles. Online PR Media. Retrieved from Online PR Media website. 2013. 
103. Fisher J, Clayton M. Who gives a tweet: assessing patients' interest in the use of social media for health care. Worldviews Evid Based Nurs. 2012;9(2):100-108.

104. Grace-Farfaglia P, Dekkers A, Sundararajan B, et al. Multinational web uses and gratifications: Measuring the social impact of online community participation across national boundaries. Electron Commer Reserch. 2006;6(1):75-101.

105. Neiger BL, Thackeray R, Van Wagenen SA, et al. Use of Social Media in Health Promotion: Purposes, Key Performance Indicators, and Evaluation Metrics. Health Promot Pract. 2012;13(2):159-164.

106. Watt JH. Improving methodology in serious games research with elaborated theory. Serious Games, Mechanisms and Effects. In: Serious Games: Mechanisms and Effects. Hoboken, NJ: Taylor and Francis; 2010. p. 374-388.

107. Lieberman DA. Video games for diabetes self-management: examples and design strategies. J Diabetes Sci Technol. 2012;6(4):802-806.

108. Crandall J. Gluten-free app reviews academy of nutrition and dietetics. Chicago, IL, USA; 2013.

109. Hall NJ, Rubin G, Charnock A. Systematic review: adherence to a glutenfree diet in adult patients with coeliac disease. Aliment Pharmacol Ther. 2009;30(4):315-330.

110. Goldberg A, Leffler DA, Tariq S, et al. Changes in body mass index on the gluten free diet: risk of obesity. Gastroenterology. 2011;140(5 Supple 1):S-439.

111. Dickey W, Kearney N. Overweight in celiac disease: prevalence, clinical characteristics, and effect of a gluten-free diet. Am J Gastroenterol. 2006;101(10):2356-2359.

112. Diamanti A, Capriati T, Basso MS, et al. Celiac disease and overweight in children: an update. Nutrients. 2014;6(1):207-220.

113. Kabbani TA, Goldberg A, Kelly CP, et al. Body mass index and the risk of obesity in coeliac disease treated with the gluten-free diet. Aliment Pharmacol Ther. 2012;35(6):723-729.

114. Cheng J, Brar PS, Lee AR, et al. Body mass index in celiac disease: beneficial effect of a gluten-free diet. $J$ Clin Gastroenterol. 2010;44(4):267-271.

115. Jafri MR, Nordstrom CW, Murray JA, et al. Long-term fracture risk in patients with celiac disease: a population-based study in Olmsted County, Minnesota. Dig Dis Sci. 2008;53(4):964-971.

116. Theodore J, Verma R, Gupta K. Celiac disease and its treatment. Top Clin Nutr. 2012;27(3):270-276.

117. Greer JM. Celiac disease and osteoporosis: An online informational brochure on lifestyle modifications to improve bone health ProQuest. Ann Arbor, MI: UMI Dissertations Publishing; 2009:50.

118. Case S. The gluten-free diet: How to provide effective education and resources. Gastroenterol. 2005;128(4):S128-S134.

119. Di Stefano M, Veneto G, Corrao G, et al. Role of lifestyle factors in the pathogenesis of osteopenia in adult coeliac disease: a multivariate analysis. Eur J Gastroenterol Hepatol. 2000;12(11):1195-1199.

120. Taler I, Phillip M, Lebenthal Y, et al. Growth and metabolic control in patients with type 1 diabetes and celiac disease: a longitudinal observational case-control study. Pediatric Diabetes. 2012;13(8):597-606.

121. Shepherd SJ, Gibson PR. Nutritional inadequacies of the gluten-free diet in both recently-diagnosed and long-term patients with coeliac disease. $J$ Hum Nutr Diet. 2013;26(4):349-358.
122. Bardella MT, Fredella C, Prampolini L, et al. Body composition and dietary intakes in adult celiac disease patients consuming a strict glutenfree diet. Am J Clin Nutr. 2000;72(4):937-939.

123. Hallert C, Grant C, Grehn S, et al. Evidence of poor vitamin status in coeliac patients on a gluten-free diet for 10years. Aliment Pharmacol Ther. 2002;16(7):1333-1339.

124. Norsa L, Shamir R, Zevit N, et al. Cardiovascular disease risk factor profiles in children with celiac disease on gluten-free diets. World $J$ Gastroenterol. 2013;19(34):5658-5664.

125. Thompson T, Dennis M, Higgins LA, et al. Gluten-free diet survey: are Americans with coeliac disease consuming recommended amounts of fibre, iron, calcium and grain foods? J Hum Nutr Diet. 2005;18(3):163-169.

126. Ludvigsson JF, James S, Askling J, et al. Nationwide cohort study of risk of ischemic heart disease in patients with celiac disease. Circulation. 2011;123(5):483-490.

127. Passananti V, Santonicola A, Bucci C, et al. Bone mass in women with celiac disease: role of exercise and gluten-free diet. Dig Liver Dis. 2012;44(5):379-383.

128. Kiskini A, Kapsokefalou M, Yanniotis S, et al. Effect of different iron compounds on wheat and gluten-free breads. J Sci Food Agric. 2010;90(7):1136-1145.

129. Nadal I, Donat E, Ribes-Koninckx C, et al. Imbalance in the composition of the duodenal microbiota of children with coeliac disease. $\mathrm{J} \mathrm{Med}$ Microbiol. 2007;56(Pt 12):1669-1674.

130. Sanz Y. Effects of a gluten-free diet on gut microbiota and immune function in healthy adult humans. Gut Microbes. 2010;1(3):135-137.

131. Golfetto L, Senna FD, Hermes J, et al. Lower bifidobacteria counts in adult patients with celiac disease on a gluten-free diet. Arq Gastroenterol. 2014;51(2):139-143.

132. Nistal E, Caminero A, Vivas S, et al. Differences in faecal bacteria populations and faecal bacteria metabolism in healthy adults and celiac disease patients. Biochimie. 2012;94(8):1724-1729.

133. Tavakkoli A, Green PH. Probiotic therapy for celiac disease. J Clin Gastroenterol. 2013;47(2):101-103.

134. Fernandez-Feo M, Wei G, Blumenkranz G, et al. The cultivable human oral gluten-degrading microbiome and its potential implications in coeliac disease and gluten sensitivity. Clin Microbiol Infect. 2013;19(9):E386-E394.

135. de Sousa Moraes LF, Grzeskowiak LM, de Sales Teixeira TF, et al. Intestinal microbiota and probiotics in celiac disease. Clin Microbiol Rev. 2014;27(3):482-489.

136. Green PH, Neugut AI, Naiyer AJ, et al. Economic benefits of increased diagnosis of celiac disease in a national managed care population in the United States. J Insur Med. 2008;40(3-4):218-228.

137. Food and Drug Administration, HHS. Food labeling: gluten-free labeling of foods. Final rule. Fed Regist. 2013;78(150):47154-47179.

138. Mangione RA, Patel PN, Shin E, et al. Determining the gluten content of nonprescription drugs: information for patients with celiac disease. $J$ Am Pharm Assoc. 2011;51(6):734-737.

139. Moriarty KJ, Kasim S, Liston R. Nonresponsive celiac disease due to inhaled gluten. N Engl J Med. 2007;356(24):2548-2549.

140. Alcohol and Tobacco Tax and Trade Bureau, Department of the Treasury. Revised Interim Policy on Gluten Content Statements in the Labeling and Advertising of Wine, Distilled Spirits, and Malt Beverages Number: 2014-2 February 11, 2014 US Goverment: Washington, DC, USA; 2014. 
141. Koehler P, Wieser H, Konitzer K. Chapter 4-Gluten-Free Products. In: Celiac Disease and Gluten: Multidisciplinary Challenges and Opportunities. Burlington: Elsevier Science; 2014. p.174-223.

142. Collin P, Thorell L, Kaukinen K. The safe threshold for gluten contamination in gluten-free products. Can trace amounts be accepted in the treatment of coeliac disease. Aliment Pharmacol Ther. 2004;19(12):1277-1283.

143. Thompson T. Gluten contamination of commercial oat products in the United States. N Engl J Med. 2004;351(19):2021-2022.

144. Zevallos VF, Herencia LI, Ellis HJ, et al. In vitro analysis of gluten-free foods containing quinoa ( Chenopodium quinoa Willd.). Proc Nutr Soc. 2009:67(OCE8).

145. Mangione RA, Patel PN, Shin E, et al. Determining the gluten content of nonprescription drugs: information for patients with celiac disease. $J$ Am Pharm Assoc. 2011;51(6):734-737.

146. Thompson T, Simpson S. A comparison of gluten levels in labeled gluten-free and certified gluten-free foods sold in the United States. Eur J Clin Nutr. 2014;69(2):143-146.

147. Ferretti G, Bacchetti T, Masciangelo S, et al. Celiac disease, inflammation and oxidative damage: a nutrigenetic approach. Nutrients. 2012;4(4):243-257.

148. Vincentini O, Quaranta MG, Viora M, et al. Docosahexaenoic acid modulates in vitro the inflammation of celiac disease in intestinal epithelia cells via the inhibition of cPLA2. Clin Nutr. 2011;30(4):541-546.

149. De Stefano D, Maiuri MC, Simeon V, et al. Lycopene, quercetin and tyrosol prevent macrophage activation induced by gliadin and IFNgamma. Eur J Pharmacol. 2007;566(1-3):192-199.

150. Bernardo D, Abad BM, Diez SV, et al. Ascorbate-dependent decrease of the mucosal immune inflammatory response to gliadin in coeliac disease patients. Allergol Immunopathol (Madr). 2012;40(1):3-8.

151. Suzuki T, Hara H. Role of flavonoids in intestinal tight junction regulation. J Nutr Biochem. 2011;22(5):401-408.

152. Maningat CC, Shi YC. Resistant starch: sources, applications and health benefits Chichester. West Sussex, UK: IFT Press; 2013.

153. Gibert A, Espadaler M, Canela MA, Sanchez A, Vaque C, et al. (2006) Consumption of gluten-free products: should the threshold value for trace amounts of gluten be at 20,100 or 200 p.p.m.? Eur J Gastroenterol Hepatol. 2006;18(11):1187-1195.

154. Klaus DA, Motal MC, Burger-Klepp U, et al. Increased plasma zonulin in pataients with sepsis. Biochem Med (Zagreb). 2013;23(1):107-111.

155. Catassi C, De Vitis I, Pianelli G, et al. A prospective, double-blind placebo-controlled trial to establish a safe gluten threshold for patients with celiac disease. Am J Clin Nutr. 2007;85(1):160-166.

156. Akobeng AK, Thomas AG. Systematic review: tolerable amount of gluten for people with coeliac disease. Aliment Pharmacol Ther. 2008;27(11):1044-1052.

157. Blazina S, Bratanic N, Campa AS, et al. Bone mineral density and importance of strict gluten-free diet in children and adolescents with celiac disease. Bone. 2010;47(3):598-603.

158. Sandstrom O, Rosen A, Lagerqvist C, et al. Transglutaminase IgA antibodies in a celiac disease mass screening and the role of HLA-DQ genotyping and endomysial antibodies in sequential testing. $J$ Pediatr Gastroenterol Nutr. 2013;57(4):472-476.

159. Dahlbom I, Olsson M, Forooz NK, et al. Immunoglobulin G (IgG) antitissue transglutaminase antibodies used as markers for IgA-deficient celiac disease patients. Clin Diagn Lab Immunol. 2005;12(2):254-258.

160. Vermeersch P, Geboes K, Marien G, et al. Defining thresholds of antibody levels improves diagnosis of celiac disease. Clin Gastroenterol Hepatol. 2013;11(4):398-403.
161. Husby S, Murray JA. New aspects of the diagnosis of celiac disease in children, adolescents, and adults. Mayo Clinic. 2013;88(6):540-543.

162. Toftedal P, Nielsen C, Madsen JT, et al. Positive predictive value of serological diagnostic measures in celiac disease. Clin Chem Lab Med. 2010;48(5):685-691.

163. Raivio T, Kaukinen K, Nemes E, et al. Self transglutaminase-based rapid coeliac disease antibody detection by a lateral flow method. Aliment Pharmacol Ther. 2006;24(1):147-154.

164. Carroccio A, Vitale G, Di Prima L, et al. Comparison of antitransglutaminase ELISAs and an anti-endomysial antibody assay in the diagnosis of celiac disease: a prospective study. Clin Chem. 2002;48(9):1546-1550.

165. Mozo L, Gomez J, Escanlar E, et al. Diagnostic value of anti-deamidated gliadin peptide IgG antibodies for celiac disease in children and IgAdeficient patients. J Pediatr Gastroenterol Nutr. 2012;55(1):50-55.

166. Villalta D, Tonutti E, Prause C, et al. IgG antibodies against deamidated gliadin peptides for diagnosis of celiac disease in patients with IgA deficiency. Clin Chem. 2010;56(3):464-468.

167. Hadithi M, von Blomberg BME, Crusius JBA, et al. Accuracy of serologic tests and HLA-DQ typing for diagnosing celiac disease. Ann Intern Med. 2007;147(5):294-302.

168. Clouzeau-Girard H, Rebouissoux L, Taupin JL, et al. HLA-DQ genotyping combined with serological markers for the diagnosis of celiac disease: is intestinal biopsy still mandatory? J Pediatr Gastroenterol Nutr. 2011;52(6):729-733.

169. Harrison E, Li KK, Petchey M, et al. Selective measurement of anti-tTG antibodies in coeliac disease and IgA deficiency: an alternative pathway. Postgrad Med J. 2013;89(1047):4-7.

170. Wakim-Fleming J, Pagadala MR, Lemyre MS, et al. Diagnosis of celiac disease in adults based on serology test results, without small-bowel biopsy. Clin Gastroenterol Hepatol. 2013;11(5):511-516.

171. Fasano A, Catassi C. Celiac disease. $N$ Engl $J$ Med. 2012;367(25):2419-2426.

172. Palma GD, Capilla A, Nova E, et al. Influence of milk-feeding type and genetic risk of developing coeliac disease on intestinal microbiota of infants: the PROFICEL study. PLoS One. 2012;7(2):e30791.

173. De Palma G, Nadal I, Medina M, et al. Intestinal dysbiosis and reduced immunoglobulin-coated bacteria associated with coeliac disease in children. BMC Microbiol. 2010;10(1):63.

174. Pozo-Rubio T, Olivares M, Nova E, et al. Immune development and intestinal microbiota in celiac disease. Clin Dev Immunol. 2012;2012:654143.

175. Liu E, Lee HS, Aronsson CA, et al. Risk of pediatric celiac disease according to HLA haplotype and country. $N$ Engl $J$ Med. 2014;371(1):42-49.

176. Waterland RA. Epigenetic mechanisms and gastrointestinal development. J Pediatr. 2006;149(5 Suppl):S137-S142.

177. Sellitto M, Bai G, Serena G, et al. Proof of concept of microbiomemetabolome analysis and delayed gluten exposure on celiac disease autoimmunity in genetically at-risk infants. PLoS One. 2012;7(3):e33387.

178. Welander A, Montgomery S, Ludvigsson J, et al. Breast-feeding duration and gluten introduction among mothers with celiac disease. $J$ Pediatr Gastroenterol Nutr. 2014;59(1):89-92.

179. Koning F. Pathophysiology of celiac disease. J Pediatr Gastroenterol Nutr. 2014;59(Suppl 1):S1-S4.

180. Sapone A, Bai JC, Ciacci C, et al. Spectrum of gluten-related disorders: consensus on new nomenclature and classification. BMC Med. 2012;10:13. 
181. Francesca M, Antonio P. HLA-DQA1 and HLA-DQB1 in Celiac disease predisposition: practical implications of the HLA molecular typing. $J$ Biomed Sci. 2012;19(1):88.

182. Sonti R, Green PH. Celiac disease: Obesity in celiac disease. Nat Rev Gastroenterol Hepatol. 2012;9(5):247-248.

183. Lundin KE, Sollid LM. Advances in coeliac disease. Curr Opin Gastroenterol. 2014;30(2):154-162.

184. Bonciolini V, Bonciani D, Verdelli A, et al. Newly described clinical and immunopathological feature of dermatitis herpetiformis. Clin Dev Immunol. 2012;2012:967974.

185. Samsel A, Seneff S. Glyphosate's suppression of cytochrome P450 enzymes and amino acid biosynthesis by the gut microbiome: pathways to modern diseases. Entropy. 2013;15(4):1416-1463.
186. Gibson P, Shepherd S. Food choice as a key management strategy for functional gastrointestinal symptoms. Am J Gastroenterol. 2012;107(5):657-666.

187. Lionetti E, Castellaneta S, Francavilla R, et al. Introduction of gluten, HLA status, and the risk of celiac disease in children. $N$ Engl $\mathrm{J} \mathrm{Med}$. 2014;371(14):1295-1303.

188. Vriezinga SL, Auricchio R, Bravi E, et al. Randomized feeding intervention in infants at high risk for celiac disease. $N$ Engl J Med. 2014;371(14):1304-1315. 